\title{
The impact of diabetes on prescription drug costs: the population-based Turin study
}

\author{
G. Bruno • L. Karaghiosoff • F. Merletti • G. Costa • \\ M. De Maria $\cdot$ F. Panero $\cdot$ O. Segre $\cdot$ P. Cavallo-Perin • \\ R. Gnavi
}

Received: 26 November 2007 / Accepted: 21 January 2008/Published online: 4 March 2008

(C) Springer-Verlag 2008

\begin{abstract}
Aims/hypothesis The aim of our study was to compare prescription drug costs in diabetic and non-diabetic individuals in a large population-based Italian cohort covered by the National Health System.

Methods We identified diabetic residents in Turin on 31 July 2003 through multiple independent data sources (diabetes registry, hospital discharges and prescriptions data sources). All prescriptions registered in the 12 month period 1 August 2003 to 31 July 2004 were examined to compare prevalence of treatment and costs in diabetic $(n=33,797)$ and non-diabetic individuals $(n=863,876)$. A log-linear model was employed to estimate age- and sex-adjusted ratios of costs.

Results Costs per person per year were $€ 830.90$ in diabetic patients and $€ 182.80$ in non-diabetic individuals (age- and
\end{abstract}

G. Bruno $(\bowtie) \cdot$ F. Panero $\cdot$ O. Segre $\cdot$ P. Cavallo-Perin Department of Internal Medicine, University of Turin, corso Dogliotti 14, 10126 Turin, Italy

e-mail: graziella.bruno@unito.it

L. Karaghiosoff $\cdot$ G. Costa $\cdot$ R. Gnavi

Epidemiology Unit, Piedmont Region,

Grugliasco, Turin, Italy

F. Merletti

Cancer Epidemiology Unit,

CERMS and Centre for Oncologic Prevention,

University of Turin,

Turin, Italy

M. De Maria

Environmental Epidemiology Unit,

Regional Environmental Protection Agency of Piedmont,

Grugliasco, Turin, Italy sex-adjusted rate ratio $2.8,95 \%$ CI 2.7-2.9). Diabetes treatment accounted for $18.5 \%$ of the total cost. Compared with non-diabetic individuals, the excess of expenditure was particularly high in diabetic patients aged $<45$ years (rate ratio 9.3), in those with type 1 diabetes (rate ratio 7.7) and in insulin users (rate ratio 4.8). The cost of diet-treated patients was similar to those treated with oral drugs. Diabetes was associated with an increased prevalence of treatment for most drug categories; one-third of the diabetic cohort received ACE inhibitors, anti-thrombotic drugs and statins. Conclusions/interpretation This population-based study shows that diabetes has a great impact on prescription drug costs, independently of main confounders, particularly in insulin-treated patients, suggesting that a wide range of comorbidities affect their health. Costs are expected to further increase if the transferability of knowledge provided by evidence-based guidelines on diabetic patients is completed over the coming years.

Keywords Cost of illness · Costs · Drugs · Economics · Health expenditures · Survey

\author{
Abbreviations \\ ARB angiotensin II receptor blockers \\ ATC Anatomical Therapeutic Chemical Classification \\ System \\ NHS National Health System
}

\section{Introduction}

Rising healthcare costs is one of the most serious problems facing industrialised countries [1, 2]. Among chronic 
diseases, diabetes has a major impact on national healthcare expenditure, which is expected to continue to increase over time because of the increasing prevalence of the disease $[2,3]$. Prescriptions costs have been estimated to account for $30-40 \%$ of direct costs of diabetes [3-5]. Few studies, however, have provided detailed figures of patterns and costs of drug use of diabetic patients, in spite of the relevance of updated information for optimisation of resources allocation [6-16]. More limited data are available on drugs use by drug categories and type of diabetes [11-16]. Main limitations of studies, conducted in the USA [6-8], Canada [9], Australia [10] Sweden [11], Germany [12-15] and Spain [17] are: (1) the recruitment of either clinic-based or health-insured diabetic cohorts, thus limiting the generalisability of results; (2) the limited number of recruited people, thus limiting the power of estimates; and (3) the absence of comparative data on non-diabetic people living in the same area, thus not allowing for control estimates of drug costs for strong confounding factors, such as age and sex.

A surveillance population-based programme monitoring the occurrence of diabetes through the employment of multiple data sources has been recently implemented in the city of Turin, an industrialised area in north-western Italy. The aims of this report were: (1) to estimate the impact of diabetes on overall drugs use, independently of age and sex; (2) to compare the pattern of drugs use by drug categories in diabetic and non-diabetic people; and (3) to assess heterogeneity in drugs use by sex, age groups and type of diabetes.

\section{Methods}

The study base of this report includes all residents in the city of Turin $(897,673$ inhabitants) on the prevalence date (31 July 2003). The first step of the study was to identify all people with diabetes resident in the catchment area [18]; the second step was to analyse prescriptions in the following 12 month period in order to provide individual data on prescription drug use, stratified by presence or absence of the disease.

All Italian citizens, irrespectively of social class or employment, are cared for by a general practitioner and obtain drugs as part of the National Health System (NHS). Patients with diabetes can obtain hypoglycaemic drugs, diabetes devices and laboratory testing free of charge from the NHS, provided they have certification of diabetes diagnosed by diabetologists working in public health clinics. Because of this procedure, most newly diagnosed patients attend one diabetes clinic at the onset of the disease and agree to be registered in the Piedmont Diabetes
Registry [19], including demographical information, type of diabetes, reference general practitioner and diabetologist. The Italian Standards for Diabetes Care recommend that all diabetic patients be examined two or three times per year by diabetes clinics and/or their general practitioners [20]; in the Piedmont Region most of then $(75 \%)$ are regularly tested for $\mathrm{HbA}_{1 \mathrm{c}}$ levels [21].

As described in detail elsewhere [18], three data sources including all people covered by the NHS were employed to identify diabetic patients on the prevalence date: (1) the file of all people registered in the Piedmont Diabetes Registry; (2) the file of all prescriptions of glucose-lowering drugs (Anatomical Therapeutic Chemical Classification System [ATC] code: A10A and A10B) prescribed from 1 January to 31 December to residents of the city of Turin; to reduce the chance of including false-positive individuals, we considered as individuals with the disease only those who had at least two prescriptions for glucose-lowering drugs; and (3) the file of all individuals resident in the city of Turin discharged from regional and national hospitals with a primary or secondary diagnosis of diabetes (ICD-9-CM code 250) in the period from 1 January to 31 December. All data sources were matched by a deterministic linkage procedure using the fiscal code as unique identifier, and were linked to the Turin Population Register to include only people alive on 31 July 2003. Type of diabetes was classified according to information provided by the Piedmont Diabetes Registry and by the Registry of Type 1 Diabetes of the Province of Turin [22]. People with unclassified diabetes were considered as having type 1 diabetes if they were $<30$ years old, otherwise as type 2 diabetes $(n=5,766)$.

All outpatients prescriptions registered in the 12 month period from 1 August 2003 to 31 July 2004 in the population of Turin were examined. Costs for drugs prescribed in the case of hospital stay were not considered, as they are accounted for in the total cost of hospitalisation.

Statistical analysis The cumulative cost for a drug was calculated by multiplying the units prescribed by the unit cost for each fill, using the actual drug costs, defined by governmental contracts, that were in effect at the time of dispensing. The proportions of individuals with specific prescriptions and the mean costs per treated patient were calculated for all ATC categories. Because age structure was different between diabetic and non-diabetic people, their costs were compared after direct standardisation of age- and sex-specific values, on the basis of the 2002 Italian census population. Rate ratios of costs between diabetic and non-diabetic people were estimated by using a log-linear model, adjusted for age and sex. Separate models were performed for type of diabetes (type 1 and type 2), sex and age groups $(<45,45-64,>64$ years $)$. 


\section{Results}

We identified 34,420 diabetic residents of the city of Turin on 31 July 2003, with an estimated completeness of ascertainment by a capture-recapture method of $80 \%$ [18]. The prevalence adjusted for completeness of ascertainment was $4.8 \%(95 \%$ CI $4.5-5.2)$. Cases with gestational diabetes $(n=623)$ were excluded from present analyses, which included 897,674 people, 33,797 with diabetes and 863,876 without diabetes. The mean ages of diabetic and non-diabetic individuals were 67.7 and 44.3 years, respectively. Of the diabetic cohort, $21.0 \%$ were treated with diet, $52.8 \%$ with oral drugs and $26.3 \%$ with insulin. There were 1,704 patients with type 1 diabetes, 26,327 with type 2 and 5,766 with undefined type of diabetes; in the final analyses, the latter cases were considered as type 2, giving a final number of 32,093 patients with type 2 diabetes.

As shown in Table 1, the overall mean prescription drug cost was $€ 830.90$ per year in diabetic patients and $€ 182.80$ per year in non-diabetic individuals. Estimates derived by $\log$-linear models showed that drugs use and costs were almost threefold higher in diabetic than in non-diabetic individuals (rate ratio $2.8,95 \%$ CI $2.7-2.9$ ), independently of age and sex. The excess of expenditure was particularly high in individuals aged $\leq 45$ years, having ninefold higher costs than non-diabetic individuals, in type 1 diabetic patients (nearly eightfold higher) and in insulin users (fivefold higher). The cost of diabetic patients treated with diet only was similar to that of those treated with oral drugs. Glucose-lowering drugs (ATC A10) accounted for $18.5 \%$ of total cost, $44.9 \%$ in type 1 and $17.0 \%$ in type 2 diabetes.

Over a 12 month study period, drugs were prescribed to $535,304 / 863,876(62.0 \%)$ non-diabetic individuals and 32,561/33,797 (96.3\%) diabetic patients. Table 2 shows that the overall age- and sex-standardised cost per treated individual per year was $€ 238.10$ for non-diabetic individuals and $€ 713.00$ for diabetic patients.

With regard to non-diabetic patients of similar age and sex, diabetic patients employed more drugs in every ATC category. Rate ratios ranged from 1.16 for anti-arrhythmic drugs to 6.54 for fibrates (Table 2) and were statistically significant; the only drugs with lower use in diabetic patients were oestrogens (rate ratio $0.70,95 \%$ CI 0.68 0.71 ) and anti-parasitic products, insecticides and repellents (ATC P; rate ratio 0.96, 95\% CI 0.93-0.98).

As regards cardiovascular drugs, they were threefold more prescribed to diabetic than non-diabetic people, independently of age and sex (rate ratio 3.29). After excluding glucose-lowering medications, they accounted for $46.2 \%$ of the total drug cost in the diabetic population (39.2\% of type 1 and $47.4 \%$ of type 2 diabetes) vs $33.2 \%$ in the non-diabetic population. Diabetic patients treated with statins were only 8,401 , whereas 1,039 were treated with

Table 1 Prescription drug costs in diabetic and non-diabetic individuals in the Turin Study

\begin{tabular}{|c|c|c|c|c|c|c|c|}
\hline & \multicolumn{3}{|c|}{ Diabetic patients } & \multicolumn{3}{|c|}{ Non-diabetic individuals } & \multirow{3}{*}{$\begin{array}{l}\text { Rate ratio }{ }^{a} \text { diabetes/ } \\
\text { non-diabetes }(95 \% \mathrm{CI})\end{array}$} \\
\hline & \multirow[t]{2}{*}{$n(\%)$} & \multicolumn{2}{|c|}{$\begin{array}{l}\text { Prescription cost } \\
\text { (€ per patient per year) }\end{array}$} & \multirow[t]{2}{*}{$n(\%)$} & \multicolumn{2}{|c|}{$\begin{array}{l}\text { Prescription cost } \\
(€ \text { per person per year) }\end{array}$} & \\
\hline & & $\begin{array}{l}\text { Not } \\
\text { standardised }\end{array}$ & $\begin{array}{l}\text { Age- and sex- } \\
\text { standardised }\end{array}$ & & $\begin{array}{l}\text { Not } \\
\text { standardised }\end{array}$ & $\begin{array}{l}\text { Age- and sex- } \\
\text { standardised }\end{array}$ & \\
\hline \multicolumn{8}{|l|}{ Age (years) } \\
\hline$<45$ & $1,673(5.0)$ & 589.60 & 569.30 & $450,496(52.1)$ & 57.00 & 55.00 & $9.3(8.0-10.8)$ \\
\hline $45-64$ & $10,735(31.8)$ & 770.30 & 751.50 & $232,483(26.9)$ & 208.00 & 205.00 & $3.5(3.3-3.7)$ \\
\hline$>64$ & $21,389(63.3)$ & 880.20 & 872.50 & $180,897(20.9)$ & 463.90 & 466.20 & $1.9(1.8-1.9)$ \\
\hline \multicolumn{8}{|l|}{ Sex } \\
\hline Men & $17,153(50.8)$ & 841.10 & 666.70 & $412,493(47.7)$ & 176.80 & 181.50 & $2.8(2.7-3.0)$ \\
\hline Women & $16,644(49.2)$ & 820.40 & 679.70 & $451,383(52.3)$ & 188.40 & 162.70 & $2.7(2.6-2.9)$ \\
\hline \multicolumn{8}{|c|}{ Type of diabetes } \\
\hline Type 1 & $1,704(5.0)$ & 887.80 & 846.20 & - & - & - & $7.7(6.8-8.8)$ \\
\hline Type 2 & $32,093(95)$ & 827.90 & 542.20 & - & - & - & $2.5(2.4-2.6)$ \\
\hline Treatment & & & & & - & - & \\
\hline Diet & $7,090(21.0)$ & 592.70 & 376.60 & - & - & - & $1.9(1.8-2.1)$ \\
\hline Oral drugs & $17,830(52.8)$ & 734.70 & 420.60 & - & - & - & $2.2(2.1-2.3)$ \\
\hline Insulin & $8,877(26.3)$ & $1,214.40$ & 939.40 & - & - & - & $4.6(4.3-4.9)$ \\
\hline Total & $33,797(100)$ & 830.90 & 671.90 & $863,876(100)$ & 182.80 & 169.70 & $2.8(2.7-2.9)$ \\
\hline
\end{tabular}

${ }^{a}$ Derived by log-linear models 
Table 2 Prescription drug costs (age and sex-standardised) in diabetic and non-diabetic individuals in the Turin Study, by ATC categories

\begin{tabular}{|c|c|c|c|c|c|c|c|}
\hline \multirow[t]{2}{*}{ ATC codes } & \multicolumn{2}{|c|}{ Prevalence of treatment $(\%)$} & \multicolumn{2}{|c|}{$\begin{array}{l}\text { Cost per person } \\
\text { per year }(€)\end{array}$} & \multicolumn{2}{|c|}{$\begin{array}{l}\text { Cost per treated } \\
\text { person per year }(€)\end{array}$} & \multirow{2}{*}{$\begin{array}{l}\text { Rate ratio }{ }^{\mathrm{a}} \text { diabetes } \\
\text { non-diabetes } \\
(95 \% \mathrm{CI})\end{array}$} \\
\hline & $\begin{array}{l}\text { Non-diabetes } \\
(n=863,876)\end{array}$ & $\begin{array}{l}\text { Diabetes } \\
(n=33,797)\end{array}$ & $\begin{array}{l}\text { Non- } \\
\text { diabetes }\end{array}$ & Diabetes & $\begin{array}{l}\text { Non- } \\
\text { diabetes }\end{array}$ & Diabetes & \\
\hline A Gastrointestinal (not A10) & 16.6 & 34.4 & 16.60 & 28.30 & 79.70 & 116.40 & $1.57(1.51-1.63)$ \\
\hline B Haematological & 11.6 & 42.4 & 10.10 & 22.50 & 131.80 & 111.00 & $2.25(1.17-2.33)$ \\
\hline B01AA Oral anticoagulants & 1.2 & 5.5 & 0.20 & 0.40 & 16.80 & 12.40 & $2.15(2.10-2.20)$ \\
\hline B01AC Anti-thrombotic & 6.4 & 32.4 & 1.50 & 4.10 & 17.20 & 25.50 & $3.42(3.33-3.52)$ \\
\hline C Cardiovascular & 23.0 & 77.1 & 56.30 & 182.10 & 173.80 & 303.20 & $3.29(3.18-3.41)$ \\
\hline C01AA Digitalis & 1.3 & 6.4 & 0.20 & 0.40 & 14.30 & 10.40 & $2.45(2.40-2.50)$ \\
\hline C01B Anti-arrhythmics & 0.6 & 2.0 & 0.50 & 0.60 & 103.80 & 35.80 & $1.16(1.13-1.19)$ \\
\hline C01DA Nitrates & 1.8 & 12.6 & 1.90 & 5.80 & 60.40 & 76.00 & $4.84(4.71-4.97)$ \\
\hline C02 Central antihypertensive & 2.3 & 12.3 & 3.60 & 13.50 & 123.60 & 144.00 & $3.67(3.55-3.79)$ \\
\hline C03 Diuretics & 5.8 & 25.9 & 1.60 & 4.90 & 22.70 & 30.60 & $3.40(3.30-3.50)$ \\
\hline C07 Beta-blockers & 5.8 & 18.0 & 3.40 & 7.30 & 53.30 & 61.40 & $1.97(1.91-2.03)$ \\
\hline $\mathrm{C} 08 \mathrm{Ca}$ antagonists & 6.1 & 27.8 & 8.00 & 21.40 & 99.50 & 115.40 & $2.83(2.73-2.92)$ \\
\hline C09 ACE inhibitors & 13.8 & 56.6 & 24.40 & 68.90 & 137.10 & 169.50 & $2.87(2.77-2.97)$ \\
\hline C09C ARB & 2.5 & 11.2 & 5.00 & 14.90 & 169.20 & 165.30 & $2.83(2.74-2.93)$ \\
\hline C09D ARB+diuretics & 2.0 & 7.1 & 4.30 & 8.80 & 168.20 & 160.50 & $2.02(1.95-2.08)$ \\
\hline C10 Lipid-lowering & 5.4 & 30.4 & 12.60 & 59.50 & 184.90 & 267.50 & $4.54(4.38-4.71)$ \\
\hline C10AA Statins & 4.4 & 24.9 & 10.20 & 40.60 & 182.20 & 230.00 & $4.14(4.00-4.28)$ \\
\hline C10AB Fibrates & 0.4 & 3.1 & 0.20 & 1.60 & 41.10 & 49.90 & $6.54(6.38-6.69)$ \\
\hline D Dermatological & 1.0 & 2.0 & 0.70 & 0.90 & 73.60 & 52.90 & $1.50(1.46-1.55)$ \\
\hline G Urogenital & 8.1 & 11.4 & 10.40 & 11.90 & 111.00 & 194.30 & $1.25(1.21-1.30)$ \\
\hline G04B Androgens & 0.2 & 0.6 & 0.30 & 0.30 & 103.90 & 33.40 & $1.05(1.02-1.07)$ \\
\hline G03C Oestrogens & 1.6 & 1.6 & 0.50 & 0.40 & 27.20 & 15.30 & $0.70(0.68-0.71)$ \\
\hline H Hormones & 7.1 & 12.8 & 4.20 & 13.80 & 189.50 & 97.60 & $3.76(3.62-3.89)$ \\
\hline J Antimicrobial & 36.6 & 51.2 & 17.70 & 34.80 & 47.60 & 72.80 & $1.76(1.71-1.82)$ \\
\hline L Antineoplastic & 1.2 & 2.8 & 15.50 & 30.10 & $1,402.50$ & $1,292.50$ & $1.71(1.64-1.78)$ \\
\hline M Antirheumatic & 18.3 & 44.8 & 6.70 & 9.50 & 25.20 & 38.00 & $1.38(1.34-1.43)$ \\
\hline N Analgesic & 8.4 & 17.7 & 18.40 & 31.40 & 236.40 & 223.30 & $1.44(1.38-1.50)$ \\
\hline $\begin{array}{l}\text { P Anti-parasitic products, insecticides } \\
\text { and repellents }\end{array}$ & 0.9 & 0.9 & 0.20 & 0.4 & 22.20 & 27.60 & $0.96(0.93-0.98)$ \\
\hline R Respiratory & 9.8 & 15.3 & 11.30 & 15.80 & 103.70 & 119.70 & $1.29(1.25-1.34)$ \\
\hline S Sensory organs & 2.1 & 8.6 & 3.10 & 6.60 & 117.50 & 100.50 & $2.11(2.05-2.19)$ \\
\hline V Various & 0.2 & 1.3 & 2.00 & 4.80 & $1,071.60$ & 499.80 & $2.75(2.66-2.85)$ \\
\hline Diabetes-related drugs & 0.9 & 79.0 & 0.60 & 278.00 & 64.60 & 344.40 & \\
\hline Total & 62.0 & 96.3 & 169.70 & 671.90 & 238.10 & 713.00 & $2.79(2.70-2.87)$ \\
\hline
\end{tabular}

${ }^{\text {a }}$ Derived by log-linear models

$\mathrm{ACE}$, angiotensin converting enzyme

fibrates, giving an overall prevalence of these treatments of $28.0 \%$ (17.3\% in type 1 and $28.5 \%$ in type 2 diabetes). One-third of diabetic people received anti-thrombotic treatment, mainly aspirin $(32.4 \% ; 19.3 \%$ type 1 and $33.1 \%$ type 2).

The employment of drugs for erectile dysfunction was very low in the overall population and only slightly higher in diabetic patients $(n=205,0.6 \%$ diabetic patients vs $1,858,0.2 \%$ non-diabetic individuals).

Table 3 shows higher rate ratios of use and drug costs in type 1 than in type 2 diabetic patients in most ATC categories, including anti-thrombotic drugs, ACE inhibitors, angiotensin II receptor blockers (ARB), antimicrobial drugs, non-steroidal anti-inflammatory drugs and analgesic drugs (Table 3). Increased prescriptions of hormonal drugs were mainly for thyroid hormones. The excess of prescriptions for anti-neoplastic drugs was evident for type 1 diabetes (rate ratio 5.46, 95\% CI 4.60-6.48), even if analyses are based on 49 individuals only.

\section{Discussion}

This study provides the first population-based data on patterns and costs of drugs use in a large southern European cohort of diabetic and non-diabetic individuals covered by 
Table 3 Rate ratios of prescription drug costs between diabetic and non-diabetic people in the Turin Study, by ATC categories and type of diabetes

\begin{tabular}{|c|c|c|}
\hline \multirow[t]{2}{*}{ ATC codes } & \multicolumn{2}{|c|}{$\begin{array}{l}\text { Rate ratio }{ }^{\text {a }} \text { diabetes/non-diabetes } \\
(95 \% \mathrm{CI})\end{array}$} \\
\hline & $\begin{array}{l}\text { Type } 1 \\
(n=1,704)\end{array}$ & $\begin{array}{l}\text { Type } 2 \\
(n=32,093)\end{array}$ \\
\hline $\begin{array}{l}\text { A Gastrointestinal } \\
\text { (not A10) }\end{array}$ & $2.85(2.44-3.33)$ & $1.50(1.44-1.55)$ \\
\hline B Haematological & $4.15(3.54-4.86)$ & $2.14(2.06-2.23)$ \\
\hline $\begin{array}{l}\text { B01AA Oral } \\
\text { anticoagulants }\end{array}$ & $2.33(2.12-2.57)$ & $2.14(2.09-2.19)$ \\
\hline B01AC Anti-thrombotic & $9.31(8.30-10.45)$ & $3.10(3.02-3.19)$ \\
\hline C Cardiovascular & $6.59(5.68-7.66)$ & $3.11(3.01-3.22)$ \\
\hline C01AA Digitalis & $2.26(2.08-2.45)$ & $2.46(2.41-2.52)$ \\
\hline C01B Anti-arrhythmics & $0.63(0.56-0.70)$ & $1.18(1.15-1.22)$ \\
\hline C01DA Nitrates & $6.53(5.82-7.33)$ & $4.75(4.62-4.89)$ \\
\hline $\begin{array}{l}\text { C02 Central } \\
\text { antihypertensive }\end{array}$ & $4.98(4.34-5.72)$ & $3.60(3.48-3.72)$ \\
\hline C03 Diuretics & $5.32(4.71-6.01)$ & $3.29(3.20-3.39)$ \\
\hline C07 Beta-blockers & $2.42(2.11-2.78)$ & $1.94(1.88-2.01)$ \\
\hline $\mathrm{C} 08 \mathrm{Ca}$ antagonists & $5.24(4.54-6.04)$ & $2.69(2.60-2.79)$ \\
\hline C09 ACE inhibitors & $7.00(6.02-8.13)$ & $2.65(2.56-2.74)$ \\
\hline C09C ARB & $5.96(5.15-6.88)$ & $2.66(2.57-2.76)$ \\
\hline C09D ARB+diuretics & $2.92(2.54-3.36)$ & $1.97(1.90-2.03)$ \\
\hline C10 Lipid-lowering & $8.64(7.40-10.07)$ & $4.32(4.17-4.48)$ \\
\hline C10AA Statins & $10.75(9.26-12.48)$ & $3.78(3.65-3.92)$ \\
\hline C10AB Fibrates & $5.77(5.22-6.37)$ & $6.58(6.43-6.74)$ \\
\hline D Dermatological & $1.36(1.19-1.56)$ & $1.51(1.47-1.56)$ \\
\hline G Urogenital & $1.94(1.65-2.27)$ & $1.22(1.17-1.27)$ \\
\hline G04B Androgens & $0.48(0.44-0.53)$ & $1.08(1.05-1.10)$ \\
\hline G03C Oestrogen & $1.05(0.95-1.16)$ & $0.68(0.66-0.69)$ \\
\hline H Hormones & $7.09(6.09-8.26)$ & $3.57(3.44-3.70)$ \\
\hline J Antimicrobial & $5.46(4.60-6.48)$ & $1.74(1.68-1.80)$ \\
\hline L Antineoplastic & $5.46(4.60-6.48)$ & $1.51(1.45-1.57)$ \\
\hline M Antirheumatic & $1.58(1.38-1.80)$ & $1.37(1.33-1.42)$ \\
\hline N Analgesic & $1.47(1.24-1.75)$ & $1.44(1.38-1.50)$ \\
\hline $\begin{array}{l}\text { P Anti-parasitic products, } \\
\text { insecticides and repellents }\end{array}$ & $1.44(1.29-1.62)$ & $0.93(0.90-0.95)$ \\
\hline R Respiratory & $1.20(1.02-1.41)$ & $1.30(1.25-1.35)$ \\
\hline S Sensory organs & $4.14(3.59-4.78)$ & $2.00(1.93-2.07)$ \\
\hline V Various & $1.37(1.19-1.58)$ & $2.83(2.74-2.93)$ \\
\hline Total & $7.72(6.78-8.79)$ & $2.51(2.44-2.59)$ \\
\hline
\end{tabular}

${ }^{a}$ Derived by $\log$-linear models

$\mathrm{ACE}$, angiotensin converting enzyme

the NHS. Our results extend previous observations on this issue in several ways. First, we confirm that diabetes care has a large impact on prescription drug costs, determining an almost threefold higher expenditure in diabetic than in non-diabetic individuals, and that this excess is independent of the main confounders, such as age and sex. Second, we point out that the excess of drugs use and cost is evident in most drug categories, particularly in insulin-treated patients, suggesting that a wide range of comorbidities affect their health. Third, we show that cost-effective drugs in the prevention of cardiovascular disease and diabetic nephropathy, such as ACE inhibitors, statins and aspirin are prescribed to one-third only of the diabetic cohort.

Few studies have provided detailed data on drug costs in diabetic and non-diabetic individuals $[14,16]$. The main limitations are the limited number of recruited diabetic patients and the absence of comparative data from the underlying non-diabetic population, not allowing control for differences in characteristics correlated with the use of healthcare services (age, sex, race/ethnicity). Data on healthcare costs of European diabetic patients were provided in 1999 by the CODE-2 study, including 7,000 type 2 diabetic patients recruited from eight European countries, which showed high variability in direct costs between countries $[4,5]$. In the subgroup of Italian diabetic patients $(n=1,263)$ the cost was $€ 2,991$ per year (range $€ 23$ $81,447)$. The study pointed out that $30 \%$ of direct healthcare costs were for drugs ( $7 \%$ glucose-lowering drugs and $21 \%$ other drugs) and $55 \%$ for hospitalisation. In contrast, in a large German population-based study using healthinsured data, cost of drugs accounted for $53 \%$ of direct costs, suggesting that CODE- 2 results could, at least in part, be explained by the selective recruitment of individuals with more severe diabetic disease [12].

Even more limited are population-based studies assessing patterns of drugs use by ATC categories and type of diabetes $[14,16]$. Our study shows that diabetic patients have higher consumptions not only of drugs directly related to prevention and treatment of cardiovascular complications, but also of drugs referring to most other ATC categories, such as antimicrobial, non-steroidal anti-inflammatory and analgesic drugs. This finding is very similar to those obtained from Germany and Scotland, in spite of different patterns of healthcare, suggesting an increased susceptibility of diabetic people to concurrent diseases, which increases related costs $[14,16]$. Given, however, the broad spectrum of drugs use, the alternative hypothesis of increased prescriptions merely because of more frequent medical access of diabetic than nondiabetic individuals of similar age and sex cannot be ruled out.

Consistent with other studies, we found that the implementation of treatment with proved efficacy and a favourable cost-effectiveness ratio such as ACE inhibitors and statins was low in our cohort $[23,24]$. Therefore, costs are expected to further increase if the transferability of knowledge provided by evidence-based guidelines on diabetic people is completed over the coming years [25].

The crucial issue of cost-of-illness studies is the identification of large and representative cohorts on a population level, which are, typically, costly to obtain, and are hence often missing. The strengths of the Turin Study are: (1) the 
availability of a large data set, allowing the comparison of prescriptions costs between almost 40,000 diabetic patients and more than 800,000 non-diabetic individuals, thus minimising the effect of large outliers on cost analyses; (2) the recruitment of a population-based cohort, thus excluding selection bias, so that data can be extrapolated to the Italian population, assuming a reasonable consistency of NHS procedures and medical approaches all over the country; and (3) the employment of multiple independent data sources, allowing the recruitment of diabetic patients treated with diet, differently from pharmaco-epidemiological studies based on a prescription database only. In our study both diabetic and non-diabetic people are covered by the universal NHS, thus allowing exclusion of the effect of selection bias on our results caused by a main confounder, such as social class. This bias may be present in studies analysing health-insured databases, where generalisability of results is limited to a subset of people, usually different from the general population.

Study limitations Our study, however, has a series of limitations: first, although multiple sources of identification were employed, $20 \%$ of diabetic patients were not captured, being probably selected for a less-severe stage of the disease and for diet-only treatment. Missing cases were analysed as non-diabetic individuals, thus determining a bias downward of rate ratios. Second, drug prescriptions rather than drugs use were analysed; however, both diabetic and non-diabetic data should have been similarly biased, thus not affecting estimated rate ratios. Third, our analyses include only drugs dispensed as part of the NHS; cheaper drugs such as aspirin could have been bought directly by the patients, whereas most other drugs, including statins, ACE inhibitors and ARB are generally dispensed as part of the NHS.

In conclusion, this large population-based study shows that diabetes care has a large impact on prescription drug costs, which are threefold higher than in non-diabetic people, probably for the treatment of comorbidities. However, costeffective drugs in the prevention of cardiovascular disease and diabetic nephropathy, such as ACE inhibitors, statins and aspirin are prescribed to one-third only of the diabetic cohort. From a public health perspective our findings suggest that costs are expected to further increase if the transferability of knowledge provided by evidence-based guidelines on diabetic patients is completed over the coming years.

Acknowledgements The Study was supported by grants from the Piedmont Region (Farmacovigilanza 2002; Ricerca Sanitaria Applicata 2003).

Duality of interest The authors declare that there is no duality of interest associated with this manuscript.

\section{References}

1. Orszag PR, Ellis P (2007) Addressing rising health care costs-a view from the Congressional Budget Office. N Engl J Med 357: 1885-1887

2. Zhang P, Engelgau MM, Norris SL, Gregg EW, Venkat Narayan KM (2004) Application of economic analysis to diabetes and diabetes care. Ann Intern Med 140:972-977

3. Hogan P, Dall T, Nikolov P, American Diabetes Association (2003) Economic costs of diabetes in the U.S. in 2002. Diabetes Care 26:917-932

4. Jönsson B, CODE-2 Advisory Board (2002) Revealing the cost of type II diabetes in Europe. Diabetologia 45:S5-S12

5. Williams R, Van Gaal L, Lucioni C, CODE-2 Advisory Board (2002) Assessing the impact of complications on the costs of type II diabetes. Diabetologia 45:S13-S17

6. Pogach LM, Hawley G, Weinstock R et al (1998) Diabetes prevalence and hospital and pharmacy use in the Veterans Health Administration (1994). Use of an ambulatory care pharmacyderived database. Diabetes Care 21:368-373

7. Weinstock RS, Hawley G, Repke D, Feuerstein BL, Sawin CT, Pogach LM (2004) Pharmacy costs and glycemic control in the Department of Veterans Affairs. Diabetes Care 27(Suppl 2):B74B81

8. Brandle M, Zhou H, Smith BR et al (2003) The direct medical cost of type 2 diabetes. Diabetes Care 26:2300-2304

9. Dawson KG, Gomes D, Gerstein H, Blanchard JF, Kahler KH (2002) The economic cost of diabetes in Canada, 1998. Diabetes Care 25:1303-1307

10. Davis WA, Knuiman MW, Hendrie D, Davis TM (2006) The obesity-driven rising costs of type 2 diabetes in Australia: projections from the Fremantle Diabetes Study. Intern Med J 36:155-161

11. Henriksson F, Agardh CD, Berne C et al (2000) Direct medical costs for patients with type 2 diabetes in Sweden. J Intern Med 248:387-396

12. Stock SA, Redaelli M, Wendland G, Civello D, Lauterbach KW (2006) Diabetes prevalence and cost of illness in Germany: a study evaluating data from the statutory health insurance in Germany. Diabet Med 23:299-305

13. Koster I, von Ferber L, Ihle P, Schubert I, Hauner H (2006) The cost burden of diabetes mellitus: the evidence from Germany. The CoDiM study. Diabetologia 49:1498-1504

14. Rathmann W, Haastert B, Roseman JM, Gries FA, Giani G (1988) Prescription drug use and costs among diabetic patients in primary health care practices in Germany. Diabetes Care 21:389-397

15. Rathmann W, Haastert B, Icks A, Giani G (2007) Trends in outpatient prescription drug costs in diabetic patients in Germany, 1994-2004. Diabetes Care 30:848-853

16. Evans JM, MacDonald TM, Leese GP, Ruta DA, Morris AD (2000) Impact of type 1 and type 2 diabetes on patterns and costs of drug prescribing: a population-based study. Diabetes Care 23:770-774

17. Oliva J, Lobo F, Molina B, Monereo S (2004) Direct health care costs of diabetic patients in Spain. Diabetes Care 27:2616-2621

18. Gnavi R, Karaghiosoff L, Costa G, Merletti F, Bruno G (2008) Socio-economic differences in the prevalence of diabetes in Italy: the population-based Turin study. Nutr Cardiovasc Dis DOI 10.1016/j. numecd.2007.11.004

19. Gnavi R, Karaghiosoff L, Dalmasso M, Bruno G (2006) The Piedmont Diabetes Register: opportunities and limits for epidemiological purposes. Epidemiol Prev 30:59-64

20. AMD, SID, Diabete Italia (2007) Standards italiani per la cura del diabete mellito. Linee guida e raccomandazioni. http://www.siditalia. it/documenti/AMD_SID_04.pdf, accessed 19 February 2008

21. Istituto Superiore di Sanità (2007) Risultati nazionali dello studo QUADRI (QUalita dell'Assestenza alle persone Dibetiche nelle 
Regioni Italiane). http://www.epicentro.iss.it/igea/pdf/Istisan_Quadri. pdf, accessed 19 February 2008

22. Bruno G, Cerutti F, Merletti F et al (2005) Residual beta-cell function and male/female ratio are higher in incident young adults than in children: the registry of type 1 diabetes of the Province of Turin, Italy, 1984-2000. Diabetes Care 28:312317

23. Winkelmayer WC, Fischer MA, Schneeweiss S, Wang PS, Levin R, Avorn J (2005) Underuse of ACE inhibitors and angiotensin II receptor blockers in elderly patients with diabetes. Am J Kidney Dis 46:1080-1087

24. Campbell HM, Boardman KD, Dodd MA, Raisch DW (2007) Pharmacoeconomic analysis of angiotensin-converting enzyme inhibitors in type 2 diabetes: a Markov model. Ann Pharmacother 41:1101-1110

25. Crivera C, Suh DC, Huang ES et al (2006) The incremental costs of recommended therapy versus real world therapy in type 2 diabetes patients. Curr Med Res Opin 22:2301-2311 